\title{
Global Production Networks and Audiovisual Industry
}

\author{
Bilyana Tomova \\ Department of Media and Public Communications, The University of National and \\ World, Bulgaria
}

\section{Глобалните производствени мрежи и аудиовизуалната индустрия}

\section{Биляна Томова}

Катедра „Медии и обществени комуникации“, Университет за национално и световно стопанство, България

\begin{abstract}
Author Note
Bilyana Tomova (i) https://orcid.org/0000-0002-7784-5453

Bilyana Tomova has no known conflict of interest to disclose.

2.1. The author of the article expresses her gratitude to the project "Creative Industries Cultural Economy Production Network" - "CICERONE", funded by the EU's research and innovation program "Horizon 2020", grant agreement № 822778. Correspondence, concerning this article should be addressed to Bilyana Tomova, University of National and World Economy, 1700 Sofia, Student Town, UNWE, New Building, Office 3090.
\end{abstract} Email: tomova@unwe.bg

\section{Бележки за автора}

Биляна Томова (i) https://orcid.org/0000-0002-7784-5453

Биляна Томова няма конфликт на интереси.

Авторьт на статията изразява благодарност към проект „Creative Industries Cultural Economy Production Network“— „CICERONE“, финансиран по програмата на Европейския съюз за научноизследователска и иновационна дейност „Хоризонт 2020“, споразумение за безвъзмездна финансова помощ № 822778. Адрес за кореспонденция във връзка със статията: Биляна Томова, София 1700, Студентски град, Нова сграда, кабинет 3090. Email: tomova@unwe.bg 


\begin{abstract}
The aim of the article is to present the concept of global production networks (GPNs) through the prism of the audiovisual industry (focus - film industry). The theory of global production networks is relatively new and is associated mainly with classical industries such as automotive, textile industry and others. Its application to the field of cultural industries goes beyond the economic dimensions and emphasizes the cultural and socio-political aspects of global markets. Global production networks are the framework in which the main trends in the audiovisual industry over the last decade will be interpreted, as well as the main stages and market players in the film industry.
\end{abstract}

Keywords: global production network, audiovisual industry, film industry

\title{
Резюме
}

Целта на доклада е да представи концепцията за глобалните производствени мрежи (ГПМ) през призмата на аудиовизуалната индустрия (фокус - филмова индустрия).

Теорията за глобалните производствени мрежи е сравнително нова и се свързва основно с класически производства като автомобилостроене, текстилна индустрия и др. Прилагането и към сферата на културните индустрии надхвърля икономическите измерения и подчертава културните и социално-политически аспекти на глобалните пазари. Глобалните производствени мрежи са рамката в която ще се интерпретират и основните тенденции в аудиовизуалната индустрия през последното десетилетие, както и основните етапи и пазарни играчи във филмовата индустрия.

Ключови думи: глобални производствени мрежи, аудиовизуална индустрия, филмова индустрия

\author{
ARTICLE INFO: \\ Original Article \\ Received: 18, 02.2021 \\ Revised: 16, 03.2021 \\ Accepted: 20, 03.2021
}




\section{Глобалните производствени мрежи и аудиовизуалната индустрия Въведение}

Концепцията за глобалните производствени мрежи (Global Production Networks) e интердисциплинарно изследователско поле и е сравнително нова в областта на икономическия анализ. Тази много аспектна теория отговаря на сложността на съвременния свят, отразявайки нарастващата глобализация през призмата на различни научни полета (икономическа география, социология, икономика, международна търговия, политически науки, както и в сектори като селско стопанство, автомобилостроене, туризъм и др.). Корените на подхода „глобални производствени мрежи“ (ГПМ) можем да открием още в теорията на Майкъл Портър (Poter,1985) за конкурентните предимства свързани с веригата на създаване на стойността. А за един от първите анализи в това ново изследователско поле се приема статията на Гари Джарафи от 1994 г. относно измененията във веригата на стойността в епохата на глобалния капитализьм.

Нарастващата глобализация дава основание на много изследователи да поставят веригата на стойността (творческа идея или създаване - производство - дистрибуция потребление - архив) в географски измерения, които надхвърлят националните пазари. В теоретичен аспект понятието Глобална производствена мрежи се развива във времето. Появило се през 90- те години на миналия век, днес много автори приемат припокриване на гледни точки и съвместна еволюция на три теории в тази посока - относно стоковата верига, веригата на стойността и производствената мрежа. (Coe, Yeung, 2015; Gereffi, 2019 цит. по Coe N., Yeung, H. 2019)

„На онтологично ниво трите концептуализации са обосновани във варианти на мрежов / верижен подход. На епистемологично ниво се занимават с „разбиране на социалната динамика на развитието на съвременния капитализъм в глобално-локалната връзка“ (Bair, J. 2005, p.154 цит. по Coe et al, 2008). Нелсън, Притчард и Йеунг предлагат дефиниция фокусирана върху спецификата на подхода „обясняващ географските модели на създаване, задържане и пленяване на стойност в глобалната икономика предимно чрез концептуалната архитектура на управлението на веригата и динамиката на мрежата - способността на водещчите фирми (фирма-лидер) да координират дейностите с добавена стойност на множество икономически актьори“(Neilson et al., 2014, p.1).

Глобализацията променя начина на производство. Днес както огромни мултинационални компании, така и малки и средни фирми са част от глобалните производствени мрежи. 
Според някои изследователи като Г. Ланца, К. Фердоус, С. Кара (Lanza et al., 2019) ГПМ могат да се проектират и развиват. Те могат и да се управляват като е водеща мисията и стратегията на фирмата лидер, в която е съсредоточена властта и възможността за създаване, пленяване на стойност: „Преминаването от централизирани производствени предприятия към производство в мрежи датира от 90-те години....Съответно глобалната производствена мрежа се състои от географски разпръснати производствени единици, които са взаимосвързани от материални, информационни и финансови потоци. Всички производствени единици извършват дейности с пряко добавяне на стойност по обща стратегия на компанията. Цялостната мрежова структура и взаимоотношенията вътре са относително стабилни. Ядро е производството, което обикновено се допълва с дистрибуторски центрове и мрежи - с цел ефективното достигане до пазарите и клиентите“ (Gisela et al., 2019).

\section{Материали и методи}

Глобалната производствена мрежа е както подход за анализ, така и форма на териториална организация, а според Коу и Йеунг (Coe, Yeung, 2019, р. 4) и „географски евристичен инструмент за картографиране“ на променените отношения между национално (локално) и глобално в икономическата система. В настоящата статия Глобалната производствена мрежа е ползвана като подход за анализ на филмовата индустрия, стъпвайки върху преглед на наличната литература и търсейки валидиране на тази нова изследователска призма в контекста на българската филмова индустрия.

Глобалните производствени мрежи като форма на организация в производствения сектор вече представляват близо 80\% от световната търговия. Факторите, които са в основата на интернационализацията на производството са свързани с търсенето на икономическа ефективност, която националния пазар не може да даде: по-ниски разходи за ресурси; развитие на нови пазари (поява на нови продукти, както и географски разширения, напр. Централна и Източна Европа, Азия); все по-ниски транспортни разходи; глобално намаляване на търговските бариери съгласно Общото споразумение за митата и търговията (ГАТТ). Малките и средните предприятия са във втората вълна на глобализация протичаща след 2000-та година, когато нарастването на глобализацията води до размиване на границите (локално-глобално) при някой продукти и услуги , а местните пазари са източник на високо квалифицирана работна сила.

Концепцията за ГПМ преосмисля: 
- $\quad$ ролята на държавата във връзката локално-глобално, като икономически субект (актьор) формиращ институционална среда, изработващ конкретни политики, засягащи пряко или косвено начина на създаване на стойност чрез трудово законодателство, фискални стимули, национални стратегии или регулации фокусирани върху преките чужди инвестиции.

- $\quad$ ролята на водещата фирма (фирма лидер) в ГПМ и начина по който тя създава и преразпределя власт (икономическа, културна) и пазарна мощ, отново в релацията глобално-локално;

- $\quad$ значението на глобалните мрежи за регионалното развитие - начинът им на „вграждане“ в местното развитие чрез възможен принос към трудови политики и познания, образование, иновации. В този аспект нараства и интересът към ролята на труда като актьор в ГПМ. Много често трудът се анализира и чрез ролята на синдикалните организации, професионални асоциации и сдружения, които могат да формират или влияят върху пазарната среда;

- $\quad$ появата на нови центрове на власт с възможност за пленяване на стойност, за контролиране на трансгранични производствени процеси, за вграждане на социални и културни навици. Тези нови центрове формират и глобалните финансови вериги на световно богатство.

Деветдесетте години са времето на възникване и на друга мултидисциплинарна концепция - за нарастващата икономическа роля на изкуствата, културните и творчески индустрии (оценени чрез инструментариума на картографирането). Обединяването под една шапка на разнородни културни дейности и превръщането им в икономически субект, създаващ добавена стойност и работни места е и нова политическа парадигма. Целта е сектор култура (вече под названието „културни и творчески индустрии“, КТИ) да стане част от икономическа действителност, където услугите са водещи, а старите, трудоемки и неефективни производства ненужен товар. Преструктурирането на икономиките в Европа, както и навлизащата дигитализация е удобния момент това да се случи. Това е и времето, в което картографирането на културния сектор в отделните страни доказва, че в културните и творчески индустрии има динамика и потенциал, не само от съзидание и талант, но и финансови средства. Тази нова парадигма измества фокуса от таланта, като създател на естетическо преживяване, към неговите икономически характеристики: възможността да се създава благосъстояние чрез култура, ролята на приходите от авторски права, културните политики като мотор да се 
възраждат местни икономики. Така КТИ чрез инструмента на картографирането се доказват като създатели на забележителен икономически растеж, работни места и нови компании, в които иновациите са както ресурс, така и продукт. А аудиовизуалната индустрия (филмова индустрия, телевизия и радио, видео игри) е с водещи показатели, както тогава, така и днес в културните и творчески индустрии.

Според новия „Пазарен анализ на културния и творчески сектор в Европа“ по данни на Евростат (за 2017 г.) на ниво ЕС културните и творчески индустрии (КТИ) създават добавена стойност от 413 милиарда евро, което представлява средно 5,5\% от добавената стойност на държавите-членки. КТИ също са и един от водещите европейски работодатели, като наемат средно 6,2\% от работната сила на ниво държава-членка през 2017 г. В страни като Холандия и Ирландия този дял надхвърля 8\%. Както заетостта, така и броят на компаниите в КТИ са нараснали като представляват средно в държавитечленки $12,1 \%$ от всички фирми. Макроикономическите показатели на КТИ са сравними и дори изпреварват показателите на много отрасли, например на сектор информационни и комуникационни технологии, факт който дава основание на ЕС да характеризира КТИ като „стратегически актив на икономиката на EC. “Вижте таблица 1.

\section{Таблица 1}

Сравнение на основните макроикономически показатели на КТИ и ИКТ

\begin{tabular}{|l|l|l|}
\hline $\begin{array}{l}\text { Основни показатели за } \\
\text { 2017г }\end{array}$ & $\begin{array}{l}\text { Информационни и } \\
\text { комуникационни } \\
\text { технологии }\end{array}$ & $\begin{array}{l}\text { Културни и творчески } \\
\text { индустрии }\end{array}$ \\
\hline $\begin{array}{l}\text { Добавена стойност, евро, в } \\
\begin{array}{l}\text { млн } \\
\text { (дял от икономиката на ЕС) }\end{array}\end{array}$ & $6,3 \%$ & 512929 \\
\hline $\begin{array}{l}\text { Заети, бр } \\
\text { (дял от икономиката на ЕС) }\end{array}$ & 5565168 & $9,5 \%$ \\
\hline $\begin{array}{l}\text { Брой компании } \\
\text { (дял от икономиката на ЕС) }\end{array}$ & 1017583 & $6,2 \%$ \\
\hline
\end{tabular}

Източник: KEA , EIF .2021

Този стратегически актив надхвърля националните граници и все по-често границите на Европа. Този факт е достатъчен да предизвика изследователски (а и не само) интерес за прилагане на Глобалните Производствени Мрежи като евристичен инструмент за анализ на КТИ.

Крачка в тази посока е и европейският изследователски проект CICERONE - Creative Industries Cultural Economy Production Network, който цели разкриване ролята на 
глобалните мрежи в КТИ, тяхното влияние за местното развитие, възможните бъдещи политики.

Анализът направен от проекта относно релевантната литература за връзката ГПМ-КТИ е сериозна база за бъдещи изследвания, защото дава методологични опори за търсене на връзката локално-глобално в интердисциплинарен контекст, стъпвайки на работата на десетки водещи изследователи, Klosterman, et al. (2021).

\section{Резултати и дискусия}

Основен двигател на растежа в КТИ в Европа е аудиовизуалния сектор (филмова индустрия, телевизия и радио, видео игри): добавената стойност е нараснала с 7.2\% между 2013 и 2017 г. и достига 185 милиарда евро, а заетите са 1,9\% от работната сила в EC. (ibid)

Показателите за КТИ, а в частност и за аудиовизуалния сектор в България са в същата забележително нарастваща тенденция. По данни на Обсерваторията по икономика на културата -София, КТИ са създали добавената стойност от 5,3\% за 2018 година, броя на предприятията в сектора расте непрекъсната през последните 10 години и вече достига 21784 компании, като преобладаващо това са микро организации. Тенденцията на заетост също е с положителна динамика и достига 108021 човека, което е 3,8\% от всички заети в България. А показателите за София, където е установено и наличието на аудиовизуален клъстер са още по-високи - всяко десето предприятие в града е от сферата на КТИ.

Срещата на тези две концепции, т.е. разглеждането на културните и творчески индустрии чрез подхода на Глобалната производствена верига започва през последните 20 години. Факт, който можем да свържем, както със спецификата на културните стоки и услуги, така и с появата на нови фактори в процеса на ГПМ - нарастващата цифровизация, отворените иновации, а в областта на медиите-конвергенцията.

Спецификата на културния продукт безспорно се отразява и на спецификата на веригата на създаване на стойността. В Европа аудиовизуалната индустрия, и в частност филмовата индустрия, е „културно изключение“, т.е. не само индустрия, а културен феномен с роля при формирането на националната идентичност. Европейските филмови пазари (с изключение на няколко големи) са квази пазар на който основна роля имат малките независими продуцентски компании, получатели на нотифицирана държавна помощ. В този пазарен контекст е силна ролята на държавата (чрез Националните 
филмови центрове), а оскъдните свободни финанси преформатират пазарната конкуренция към конкуренция за спечелване на държавна помощ (субсидия).

Размерът на европейските пазари в съчетание с над национална регулация в областта на аудиовизията предопределя съществуването на бариери за пазарна концентрация и последвалата невъзможност да има големи платформени европейски играчи. В същото време на аудиовизуалния пазар навлизат новите глобални играчи, които най-често преразпределят или пленяват, а не създават стойност на европейския континентмултимедийните платформи.

В аудиовизуалната индустрия технологичната конвергенция породи и нуждата от нови финансови ресурси, отговорът бе икономическата вълна от хоризонтални и вертикални сливания във филмовата и телевизионна индустрии, както и поява на нови, преливащи се хибридни вериги на стойността. По този начин конвергенцията стана стимул за създаване на глобални производствени структури в аудиовизията. Във филмовата индустрия чрез навлизането на инструментариума на данъчните стимули се даде възможност за преливане на средства към компании от САЩ (при висок праг за финансово участие на местни фирми). Динамиката на аудиовизуалната индустрия през последното десетилетие създаде асиметрия в силата (икономическата мом) на отделните икономически субекти във веригата. Вижте таблица 2.

\section{Таблица 2}

Верига на стойността във филмовата индустрия

\begin{tabular}{|l|l|}
\hline ЕТАПИ & ФИЛМОВА ИНДУСТРИЯ \\
\hline Създаване & $\begin{array}{l}\text { Развитие на идеята (написване на сценария, консултации на пазари } \\
\text { за идеи и проекти, напр. София миитинг, тьрсене на локации, } \\
\text { предварителни договори с основния творчески екип) }\end{array}$ \\
\hline Производство & $\begin{array}{l}\text { Финансиране (обществено финансиране - Национален филмов } \\
\text { център, копродукции европейски, частни средства, продажба на } \\
\text { права за ТВ излъчване }) \\
\text { Продукция (заснемане) и пост продукция }\end{array}$ \\
\hline Дистрибуция & $\begin{array}{l}\text { Дистрибутора купува правата за показ на конкретните територии, } \\
\text { маркетинг. Фестивални пазари. }\end{array}$ \\
\hline Показ & Показ - физически на голям екран и онлайн, ТВ ОТТ/VoD, Рау TV \\
\hline Архв & $\begin{array}{l}\text { Дигитален архив, както и възможност за последващ дъльг показ на } \\
\text { специализирани дигитални платформи }\end{array}$ \\
\hline
\end{tabular}

Бележка: По идея от KEA , EIF. (2021) съобразено с българския пазарен контекст

Ролята на държавата остана базисна, за този пазар, но дистрибуторите (основно представители на Холивудските студия) се очертаха като нов центьр на 
преразпределение на стойност. При деление на прихода от бокс офиса 50:50, което в определени периоди стана 70:30 в тяхна полза, при вертикално преливане на собственост между дистрибуция и показ, продуцентските компании бяха притиснати. Те загубиха обичайната си властваща сила, така характерна за създателите на стойност в една верига. Филмовата индустрия в аспекта на ГПМ се разглежда за първи път от Анди Пратт (Pratt, 2008), но основополагащ анализ за ролята на ГПМ в днешния аудиовизуален пазар прави Нейл Коу (Coе, 2015). Пазарните, социални и законодателни процеси протичащи днес в българския филмов контекст са точно отражение на заключенията, направени от него относно глобалните процеси, ГПМ и тяхното влияние върху европейските филмови индустрии:

- Отношенията на власт във веригата на стойността, варират според икономическите субекти в мрежата, в зависимост от структурните и информационните ресурси, с които те разполагат. На база притежаване и разпореждане с ограничен ресурс, в България се формират няколко центъра на власт и те не произлизат от самото производство, от творците на филма. Те са отражение на: икономическата власт на държавата като разпределител на финансови потоци (субсидия) и в частност НФЦ, като притежател и разпределител на бюрократична рента; властта (ролята) на професионалните асоциации, като прихващащи стойност чрез влияние при разпределението на оскъдните финансови средства, както чрез лобиране, така и чрез участие в експертни комисии, които дават достьп отново до бюрократична рента; нарастващата власт (роля) в мрежата на дистрибуторите, без чието участие не може да се осъществи социализацията и монетаризацията на създаденото съдържание (стойност);

- Асиметричният достъп до ресурси - ключови продукти и услуги, също води до възникване на рента, според Коу (Coe, 2015), а ГПМ дава възможност за достигане до някои видове рента чрез участие в копродукционни мрежи (извън националния пазар). Ако приложим подхода на ГПМ към българския контекст ще установим, че националното филмово производство има силни перспективи чрез копродукциите до допълнителни финансови средства - паневропейските програми „Медия“(Творческа Европа), „Евроимаж“, регионални фондове в отделните пазари, както и достъп до рента произтичаща от включването в продукцията на международно име -талант, бранд. Последното дава възможност до по-добро позициониране на глобалния пазар, видимост на продукта в среда на сврьх предлагане, фестивални награди и похвални оценки на критиката. А всички тези процеси добавят нова стойност към филмовия продукт. 
- Клъстерите са типичен пример за ролята на мрежата, която надхвърля резултатите от веригата на стойността (която е линейна). Така се отваря потенциала на крос секторните връзки между различни части на творческата икономика (Weller, 2008 цит. по Сое, 2015). Доказателство в тази посока е аудиовизуалния клъстер в София, който може да се характеризира като спиловър ефект от типа „мрежа“. Предприятията са обвързани от общ творчески процес, т.е. те са представители на различни части на стойностната верига при създаване и дистрибуция на културните стоки и услуги, имат някои свързани дейности, използват общи ресурси, които се преливат. „Тези характеристики на производството създават елементи на т.нар. мрежова структура. Подобни структури при определено технологично ниво (навлизане на нови технологии, иновации от различен тип) могат да създават вертикална и хоризонтална връзки, дори интеграция, т.е. създава се клъстер. Географската концентрация-обособеността на района, е задължително условие. София има обособен клъстер и той е във филмовата индустрия, която създава 97\% от икономическия си растеж в този град. Но това, което е от голямо значение за един клъстер и тук е налице, е че филмовата индустрия е обвързана с дейности като телевизионното производство, онлайн медиите, компютьрните игри, звукозаписа, фотографията, дизайна (които също са концентрирани в София) и е свързана технологично индустрия отново с телевизията, сценичните изкуства, музикалния бизнес, рекламата, дигиталните медии, книгоиздаването, образованието“ (Tomova, Andreeva, 2015, p.40);

- Природата на филмовата индустрия е международна, стремежът за дистрибуция извън националния пазар е здравословен и абсолютно задължителен. В епохата на глобализацията стремежът към интернализиране на отделни етапи във филмовата индустрия на Холивуд нараства драматично, според Коу (Сoе, 2015), като основната цел е намаляване на разходите и дисперсия на риска. ${ }^{1}$ Търсенето на решение обхваща производството, дистрибуцията, финансирането на филмовия продукт:

- Вертикална дис интеграция на производствения процес чрез пренасочване на производството в държави, градове с по-евтина работна сила, удобни локации и културна политика, където има възможност за данъчни стимули.Силната международна дистрибуционна структура, която да осигури възвращаемост от високобюджетните филми е задължителна. Добър пример е един от най-популярните 3D филми „Аватар“,

\footnotetext{
${ }^{1} \mathrm{C}$ нарастване ва бюджетите на блогбастърите и отдръпването на банковия сектор от инвестиране в киното след 2008г това става наложително.
} 
от който по данни на изчисляващия с алгоритми сайт Мојо възвращаемостта от брутния бокс офис от вътрешния пазар (САЩ и Канада) е 27,3\%, а приходите от чужбина са повече от две трети $-72,7 \%$. Вижте таблица 3 . .И този пример не е изключение, а правило за работата на холивудската дистрибутивна система. В България делът на американските филми по кината е водещ, като се движи между 92-96\%, за Европа, през последното десетилетие, средната стойност на американското присъствие е $70 \%$.

\section{Таблица 3}

Филмът „Аватар“ - приходи от билети от вътрешния и международния пазар

\begin{tabular}{|c|l|c|c|c|}
\hline \multicolumn{1}{|c|}{ Филм } & Дистрибутор & $\begin{array}{c}\text { Бюджет на } \\
\text { филма }\end{array}$ & $\begin{array}{c}\text { Вътрешен } \\
\text { брутен бокс } \\
\text { офис }\end{array}$ & $\begin{array}{c}\text { Външен } \\
\text { брутен бокс } \\
\text { офис }\end{array}$ \\
\hline Аватар (2009г) & $\begin{array}{l}\text { Туенти } \\
\text { сентъри фокс }\end{array}$ & 237 млн \$ & 749,7 млн \$ & 1,993 млрд \$ \\
\hline
\end{tabular}

Източник: по информация от

https://www.boxofficemojo.com/release/rl876971521/?ref_=bo_csw_table_3

- Показателни за дискурса на глобалната производствена мрежа е тьрсенето на американските медийни конгломерати на финансиране извън САЩ и като стимулиран отговор - появата и разпространението на данъчните стимули (рабат, данъчен кредит, намаляване на данъчната основа или ставка и др.) в Европа и света. „От гледна точка ГПМ обществените схеми за данъчни стимули се превръщат в основна стратегия за пленяване на стойност от водещите медийни конгломерати“ Коу (2015) И по този начин организацията и географията на филмовата индустрия се влияе силно от наличието на местни субсидии, които могат да бъдат усвоени.

Всъщност, данъчният кредит е данъчен приход към бюджета от който държавата се е отказала и тези средства се преврьщат в субсидия за чуждите филмови продукции (не е задължително дори да са копродукции с национално участие). От този тип инструменти на ГПМ е и данъчният кредит в България, който след десетилетие про американско лобиране, стана част от Закона за филмовата индустрия в България (февруари 2021г). Той има за цел привличане основно на американски филмови продукции и е недостьпен за българските продуценти, поради високия минимум от частни средства, като условие за тяхното участие. „Този модел води до финансиране на преди това нежизнеспособни проекти и нетния резултат е, че в глобален мащаб това е 
приток на Европейски капитал в американската индустрия чрез ко-финансови инициативи.“( Morawetz et al., 2007 цит. по Coe, 2015, p. 495)

\section{Заключение}

Световната икономика е все по-силно взаимообвързана и аудиовизуалната индустрия не прави изключение - тя е зависима от преплитането на местни и глобални производствени мрежи на всички етапи от създаването на филмовия продукт. И ако локалните клъстери са силен фактор за вертикална интеграция в културните индустрии, то стремежът към намаляване на производствения риск и търсенето на допълнително финансиране поражда де интеграция в големите мултимедийни компании, чрез интернализиране на части от веригата на създаване на стойността.

Глобализмът е идеологически и морално циментиран с неолибералната философия за пазарна ненамеса пряко на държавата, но нуждата от косвена подкрепа на пазарните субекти (с особена симпатия към международните конгломерати).

Теорията за глобалните производствени мрежи има както поддръжници, така и сериозни критици, като Бенджамин Селвин (Selwin, 2021), които класифицира глобалните вериги като създатели на неравностойни резултати, от който се облагодетелстват основно мултинационални олигополи.

Във филмовата индустрия интернализирането на отделни етапи от филмовия процес прави възможно рискът от производството да се разхвърля върху данъкоплатците на други държави с обещанието за създаване на местен просперитет чрез направените от продукцията инвестиции в конкретната територия. Данъчните стимули са друг инструмент за пленяване на стойност в ГПМ. Въпросът доколко прилагането им е икономически ефективно и данъчно справедливо много често се манипулира под натиска на политическо лобиране и ставаме свидетели на изместване на националната културна политика към про пазарна такава с несигурни ползи за местното развитие днес и устойчивостта на националните медийни системи в бъдеще.

През последната година възникват въпроси, на които все още нямаме отговор. Икономическата, социална и здравна криза породена от световната пандемия от COVID19 явно е „момент“ на де глобализация (при производството на храни, медицинско оборудване, лекарства и др.), но как ще се отрази икономическата стагнация върху развитието на глобалните производствени мрежи в аудиовизуалната индустрия? В този променен контекст анализът през призмата на глобалните производствени мрежи е особено ценен и предстои. 


\section{Използвана литература}

Bair, J. (2005). Global capitalism and commodity chains: Looking back, going forward. Competition \& Change, 9(2), 153-180. https://doi.org/10.1179/102452905X45382

Coe, N. (2015). Global production networks in the creative industries. In C. Jones, M. Lorenzenand, J. Sapsed (Eds.), The Oxford Handbook of Creative Industries (pp. 486501). Oxford University Press. DOI: 10.1093 / oxfordhb / 9780199603510.013 .014

Coe N., Dicken, P., Hess, M. (2008). Introduction: global production networks-debates and challenges, Journal of Economic Geography, 8(3), 267-269.

https://doi.org/10.1093/jeg/lbn006

Coe, N., Yeung, H. (2015). Global production networks: Theorizing economic development in an interconnected world. Oxford University Press.

DOI: 10.1093 / acprof: oso / 9780198703907.001.0001

Coe, N., Yeung, H. (2019). Global production networks: mapping recent conceptual developments, Journal of Economic Geography, 19 (4), 775-801. https://doi.org/10.1093/jeg/lbz018

Gereffi, G. (1994). The organization of buyer-driven global commodity chains: How US retailers shape overseas production networks'. In G. Gereff and M. Korzeniewicz (Eds.), Commodity Chains and Global Capitalism (pp. 95-122). Westport, CT: Prae. https://www.researchgate.net/publication/281870191_The_Organization_of_BuyerDriven_Global_Commodity_Chains_How_US_Retailers_Shape_Overseas_Production _Networks

Gereffi, G. (2019). Global value chains and development: Redefining the contours of 21st century capitalism. Cambridge University Press. DOI: 10.1017 / 9781108559423

KEA Idea consult. (2017). Mapping the creative value chains. A study on the economy of culture in the digital age: final report . DOI:102766/491907

KEA European affairs. (2021, January 15). Market analysis of the cultural and creative sectors in Europe" https://keanet.eu/publications/ https://keanet.eu/wp-content/uploads/ccs-market-analysis-europe012021_EIFKEA.pdf

Kloosterman R., Pratt A., d'Ovidio M., Greco L., \& Borén T. (2021). Creative and cultural industries in global production network approaches so far: a brief review of the literature and its relevance for the creative and cultural industries (Version 1.0). Zenodo. http://doi.org/10.5281/zenodo.4535064 
Lanza, G., Ferdows, K., Kara, S., Mourtzis, D., Schuh, G., Vancza, J. (2019). Global production networks: Design and operation, CIRP Annals, 68(2), 823-841. https://www.sciencedirect.com/science/article/pii/S0007850619301659

Morawetz, N. \& Hardy, J. \& Haslam, C., \& Randle, K. (2007). Finance, policy and industrial dynamics - the rise of co-productions in the film industry. Industry \& Innovation, 14, 421- 443. 10.1080/13662710701524072.

Neilson, J., Pritchard, B., Yeung, H. (Eds). (2014). Special issue on global value chains and global production networks in the changing international political economy. Review of International Political Economy, 21, 1-274. https://doi.org/10.1080/09692290.2013.873369

Porter, M. (1985). Competitive advantage: creating and sustaining superior performance. New York Free Press.

Pratt, A. (2005). Cultural commodity chains, culturai clusters, or chains? Grow and Change, 39(1), 95-103. DOI: 10.1111/ j.1468-2257.2007.00406.x

Selwyn, B., Leyden, D. (2021). Oligopoly-driven development: The Word Bank's trading for development in the age of global value chains in perspective. Competition \& Change. https://doi.org/10.1177/1024529421995351

Tomova, B. , Andreeva, D. (2016). Balgarskite medii: ikonomicheski prinos v transformirashta se sreda. In B. Tomova, D. Andreeva, S. Tcankova, S. Angova, M. Nikolova, I. Valchanov (Eds.), IIkonomicheski i profesionalni transformatsii v konvergentnata mediyna sreda [Bulgarian Media: Economic Contribution in a Transforming Environment. In B. Tomova, D. Andreeva, S. Tcankova, S. Angova, M. Nikolova, I. Valchanov (Eds). Economic and Professional Transformations in a Convergent Media Environment]. Newmedia21.eu. 11/07/2016 https://www.newmedia21.eu/content/2011/11/SBORNIK-za-Nyu-media-21.pdf (02.04.2021).Newmedia21.eu.

Weller, S. (2008). Beyond global production networks: Australian fashion week's truns-sectoral synergies. Growth Change, 39(1), 104-122. https://doi.org/10.1111/j.1468-2257.2007.00407.x 